Article

\title{
Dynamic Coercivity of Tempered Ferritic Steel Subjected to Creep-Fatigue for Nondestructive Evaluation by Reversible Permeability
}

\author{
Chung Seok Kim \\ Department of Materials Science and Engineering, Chosun University, Seosuk-dong, Gwangju 501-759, Korea; \\ chs2865@chosun.ac.kr; Tel.: +82-62-230-7197
}

Received: 12 February 2020; Accepted: 3 March 2020; Published: 6 March 2020

check for updates

\begin{abstract}
This study aims to characterize nondestructively the creep-fatigue damage of tempered ferritic steel by dynamic coercivity measured by reversible permeability. The creep-fatigue test was achieved under load control with a hold time of $60 \mathrm{~s}$ and $600 \mathrm{~s}$. The dynamic coercivity based on the reversible magnetic permeability profiles was successfully obtained on top of the test specimen. Based on these results, we attempted to evaluate the creep-fatigue of tempered ferritic steel with the support of microstructural evaluation such as dislocations and precipitates. The dynamic coercivity decreases with fatigue life fraction and closely related to the number of $\mathrm{Cr}_{23} \mathrm{C}_{6}$ precipitates with $N^{0.8}$ and the dislocation density with $\rho^{0.4}$ In addition, Vickers's hardness continuously decreased up to the failure deducing the softening of mechanical strength. In conclusion, it can nondestructively characterize the influence of the precipitates and dislocation density on the dynamic coercivity of ferritic steel during creep-fatigue.
\end{abstract}

Keywords: precipitates; dislocations; dynamic coercivity; creep-fatigue; nondestructive characterization

\section{Introduction}

The ferritic $9 \mathrm{Cr}$ steel has been recognized as a key material for turbines, rotors, pipes, etc. in nuclear and fossil power plants. In this ferritic low-carbon steel, the $\mathrm{Cr}$ element increases generally high-temperature creep strength, oxidation resistance, and corrosion resistance, which has superior physical and chemical properties than low $\mathrm{Cr}$ content steels [1-3]. However, mechanical softening causing strength drop and embrittlement is inevitable for high-temperature structural materials because of long-term exposure to high temperature and high pressure, such as creep and fatigue. The mechanical softening is physically evolved to the microstructural variation in a generation and coarsening of the secondary phases, the recovery of dislocations, the growth of martensite lath width, and depletion of the solute atoms [4,5]. Structural facilities subjected to high temperature and high pressure for long-term exposure can be deteriorated and fractured during their operation due to mechanical softening. Since the damage and fracture are localized and accelerated without notice, the monitoring and characterization of structural components are very important and necessary. Therefore, in-service inspections and nondestructive evaluation (NDE) methods are indispensable to evaluate safety periodically. To monitor the mechanical softening during long-term exposure, the microstructural variation should be quantified and evaluated [6-8].

Reversible magnetic permeability is the limited value of the incremental permeability when the incremental permeability is at $\Delta H \rightarrow 0$ [9]. Magnetic properties are usually measured at the fixed magnetic field applied to the test samples in most magnetic techniques. However, for the dynamic method, the modulation field is also applied in addition to the magnetization field. Then, the induction 
of the samples are obtained. The maximum permeability value generally corresponds to the coercivity field $\left(H_{\mathrm{c}}\right)$ of the sample. Under dynamic conditions, it is easy to measure the dynamic coercivity from a plot of $\mu_{\mathrm{r}}$ (reversible permeability) versus $H_{\mathrm{a}}$ (applied magnetic field), taking into account the magnitude of small modulation $H_{0}$, such as $H_{0}<<H_{\mathrm{c}}$ [10].

For many years, the magnetic properties of ferromagnetic materials have been known to depend on their microstructural characteristics, such as composition, dislocation, precipitates, and grain size. Sgobba [11] reported that the saturation magnetization is not strongly influenced by purity, while coercivity and permeability strongly depend on the purity and crystallographic features in iron. In addition, Liu et al. [12] studied the precipitates in extra-low-carbon steel by characteristic magnetic parameters measured from major and minor magnetization loops. Most of all, the dependence of coercivity on grain size is well-known to be an inverse square root relationship. The coercivity linearly increases with the reciprocal of the square root of grain size as well as theoretical calculation [13,14]. Wörner et al. assumed that coercivity is due to the pinning of Bloch walls by second-phase particles considering that the wall are rigid walls [15]. Fidler et al. investigated that the dislocation should be the Bloch wall pinning site in a similar manner to the mechanical problem of dislocation bowing of the pinning center [16]. Such relationships strongly suggest that magnetic measurements could be a potential technique as a nondestructive evaluation method for the determination of the physical properties of materials. This experimental study deals with the NDE of creep-fatigue in ferritic steel using a magnetic property to examine the effects of nonmagnetic inclusions and dislocations on the dynamic coercivity.

\section{Materials and Methods}

The ferritic 9Cr low-carbon steel was used in this study. The creep-fatigue was conducted by a servo-hydraulic fatigue test machine. It was achieved under load control with a hold time of $60 \mathrm{~s}$ and $600 \mathrm{~s}$ at the maximum tensile. The test sample was prepared with a cylindrical shape in a dimension of $16 \mathrm{~mm}$ length and $10 \mathrm{~mm}$ diameter. For the NDE test of damaged structural materials, the test coupons were prepared with different levels of creep-fatigue damages by the interruption test. The interruption time was varied on the basis of the number of fatigue cycles. Table 1 shows the creep-fatigue test parameters such as fatigue life fraction (fraction to the fracture cycle, $N_{\mathrm{f}}$ ), cycle, test duration, and total hold time.

Table 1. Creep-fatigue parameters of tempered ferritic $9 \mathrm{Cr}$ steel.

\begin{tabular}{|c|c|c|c|c|c|c|c|}
\hline \multicolumn{2}{|c|}{ Fatigue Life Fraction } & $0.1 N_{\mathrm{f}}$ & $0.2 N_{\mathrm{f}}$ & $0.4 N_{\mathrm{f}}$ & $0.6 N_{f}$ & $0.8 N_{\mathrm{f}}$ & $1 N_{\mathrm{f}}$ \\
\hline \multirow{3}{*}{$60 \mathrm{~s}$} & Cycle & 330 & 660 & 1320 & 1980 & 2640 & 3300 \\
\hline & Test duration (s) & 384 & 768 & 1536 & 2310 & 3078 & 3840 \\
\hline & Total hold time & 330 & 660 & 1320 & 1980 & 2640 & 3300 \\
\hline \multirow{3}{*}{$600 \mathrm{~s}$} & Cycle & 95 & 190 & 380 & 570 & 760 & 950 \\
\hline & Test duration (s) & 960 & 1920 & 3840 & 5790 & 7722 & 9600 \\
\hline & Total hold time & 948 & 1896 & 3738 & 5700 & 7596 & 9498 \\
\hline
\end{tabular}

To examine the morphology and crystal structure of the precipitates, a thin film specimen of carbon extraction replica was prepared and examined by transmission electron microscopy (TEM) [17]. The chemical composition of precipitates was analyzed by the energy dispersive spectroscopy (EDS). Further, the crystal structure of precipitates was evaluated by the selective area diffraction (SAD) pattern. To observe the dislocation substructures, thin foils of $3 \mathrm{~mm}$ diameter disc specimens were finally prepared by electrolytic polishing in a solution of $125 \mathrm{~mL} \mathrm{H}_{2} \mathrm{SO}_{4}$ and $875 \mathrm{~mL}$ methanol.

The X-ray diffraction patterns were obtained to measure the dislocation density with monochromatic $\mathrm{Cu} K_{\alpha 1}$ radiation using a high-resolution X-ray diffractometer (HRXRD). The plastic strain was measured by the X-ray diffraction (XRD) line profile, then converted to the breadth of 
the strain distribution using the Hall-Williamson method [18]. A surface layer of about $50 \mu \mathrm{m}$ was removed by an electrolytic polishing method in $10 \% \mathrm{Nital}$ acid at a voltage of $24 \mathrm{~V}$, before the $\mathrm{X}$-ray diffraction experiments. The micro Vicker's hardness test was carried with the same samples of optical micrograph observation after vibration polishing with $0.01 \mu \mathrm{m} \mathrm{Al}_{2} \mathrm{O}_{3}$ suspension.

A ferrite yoke type probe was applied to eliminate the demagnetization effect and wound by pickup coils, AC perturbing coils, and DC magnetizing coils. The test specimen was prepared in a dimension of $15 \mathrm{~mm} \times 7 \mathrm{~mm} \times 1 \mathrm{~mm}$ by the wire cutting process. The specimens were magnetized using a sinusoidal wave current of $0.05 \mathrm{~Hz}$ with a maximum applied magnetic field of $12.0 \mathrm{kA} / \mathrm{m}$.

The voltage was induced in the pickup coil and obtained by a lock-in amplifier (EG\&G PAR 5210). A more detailed experimental system was previously reported [19]. The reversible permeability (RP) profile can be successfully obtained during a slow varying cycle with current using an $\mathrm{I} / \mathrm{O}$ board.

The maximum permeability may correspond to the dynamic coercivity when the magnitude of the modulation field is negligible compared with coercivity. Therefore, dynamic coercivity could be obtained from the reversible permeability profile.

\section{Results and Discussion}

The dynamic coercivity was successfully obtained from the reversible permeability profile assuming the position of maximum reversible permeability. The variation in dynamic coercivity exponentially decreased as a function of fatigue cycles at each hold time, as shown in Figure 1a. The decreasing rate of $600 \mathrm{~s}$ holding time shows higher than that of $60 \mathrm{~s}$ holding time. The dynamic coercivity of the fracture at the holding time of the $60 \mathrm{~s}$ shows the same level right before fracture. However, at a holding time of $600 \mathrm{~s}$ the dynamic coercivity of the fracture increases and shows higher than right before fracture. The dynamic coercivity decreased with fatigue cycles showing a magnetically softening phenomenon. The magnetization is physically related to the domain wall motion, and the coercivity depends on the degree of pinning of the domain wall. Therefore, inclusions, dislocation, and grain boundary may hinder the domain wall movement, which are potentials of pinning sites of the domain wall. We investigate microstructural evolution during creep-fatigue damage of $9 \mathrm{Cr}$ steel with the support of microstructural observation techniques. The Vickers's hardness continuously dropped, indicating mechanical softening. Figure $1 \mathrm{~b}$ depicts the relationship between Vicker's hardness and dynamic coercivity showing good linear relation and high R-square of 0.9. Byeon et al. also reported that the good correlations of magnetic coercivity with Vicker's hardness. They studied magnetic coercivity of $2.25 \mathrm{Cr}$ steel subjected to long-term thermal aging and showed the precipitate dependence on the magnetic coercivity [20]. Most metallic components undergo mechanical softening during their high-temperature and high-pressure exposure due to the coarsening of the secondary phases and the recovery of dislocations resulting in a decrease in mechanical strength [21]. Therefore, this dynamic coercivity should be a potential method to evaluate the degradation of structural materials.

Figure 2 shows the TEM micrographs at each fatigue cycle and the SAD pattern of precipitates. The martensitic lath structures consist of dislocation substructures and fine precipitates.

The as-tempered specimen shows a typical martensite structure as shown in Figure 2. The previous austenite grain (PAG) size was $20 \mu \mathrm{m}$ and the lath width was $0.21 \mu \mathrm{m}$. The PAG size does not change during the test. The tempered ferritic $9 \mathrm{Cr}$ steel showed elongated lath substructures, as shown in Figure 2a. The dislocations were tangled with a high density. The dislocation density decreased with the creep-fatigue test of $0.2 N_{f}$ (see Figure $2 b$ ). The martensite lath continuously increased with creep-fatigue (see Figure 2c) and the dislocation density was lower than in Figure 2a. The growth of the lath width is attributed to the recovery of dislocations within and recombination of the lath boundaries due to the migration of the lath boundary [22]. The dislocation density of each deformed sample was calculated by the XRD strain measurement. 

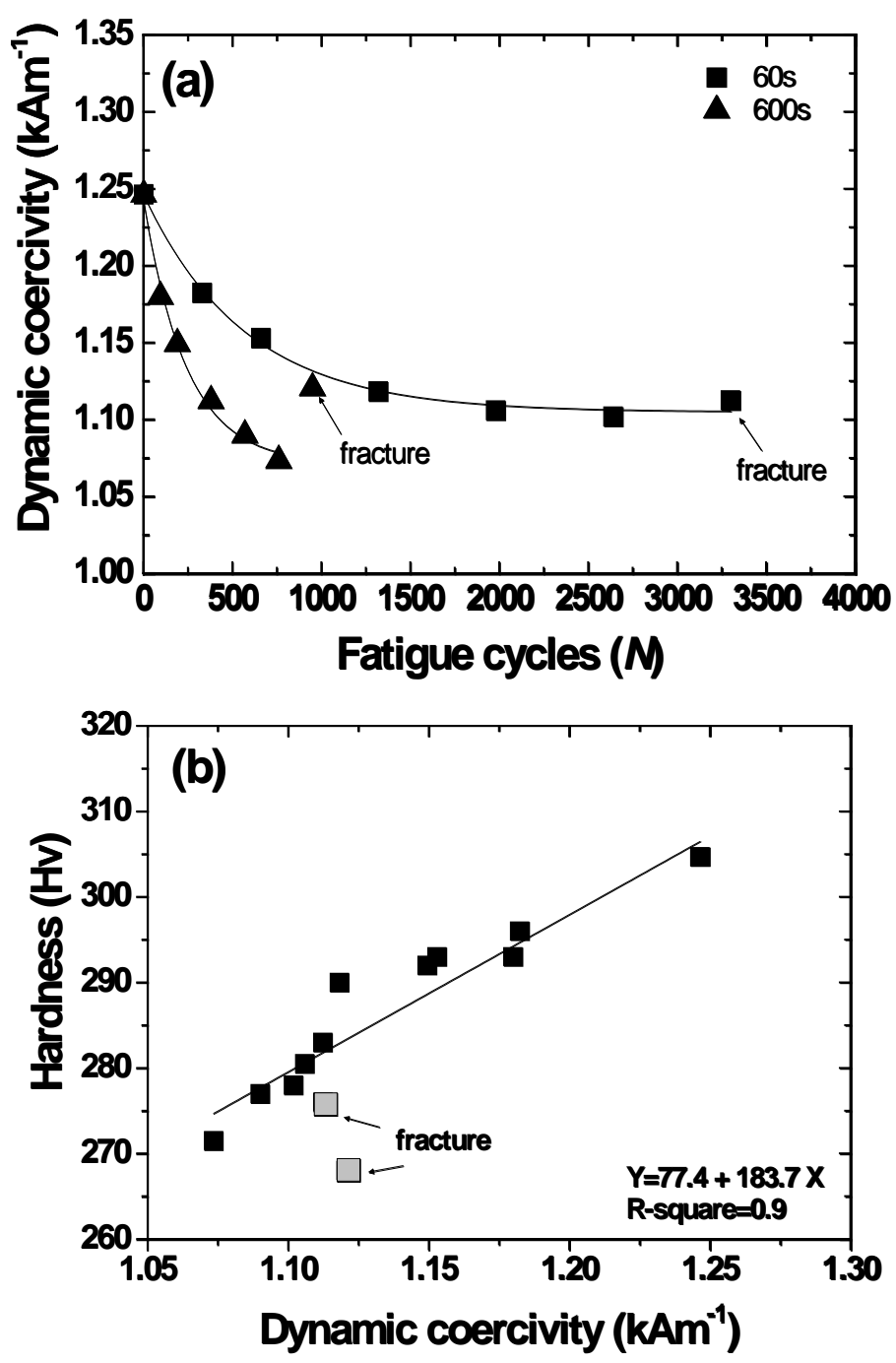

Figure 1. Variation in dynamic coercivity and Vicker's hardness; (a) dynamic coercivity with fatigue cycles and (b) correlation between hardness and dynamic coercivity.

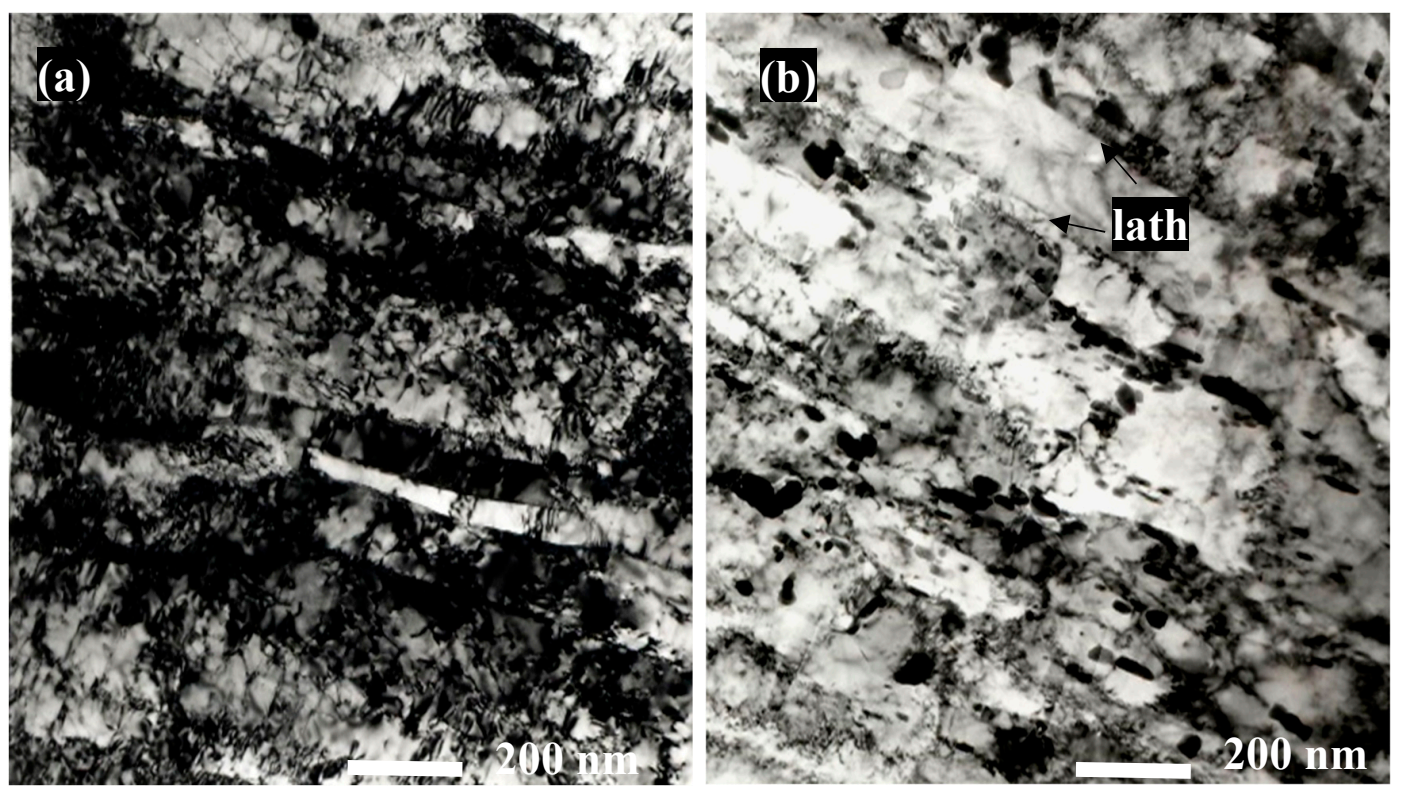

Figure 2. Cont. 

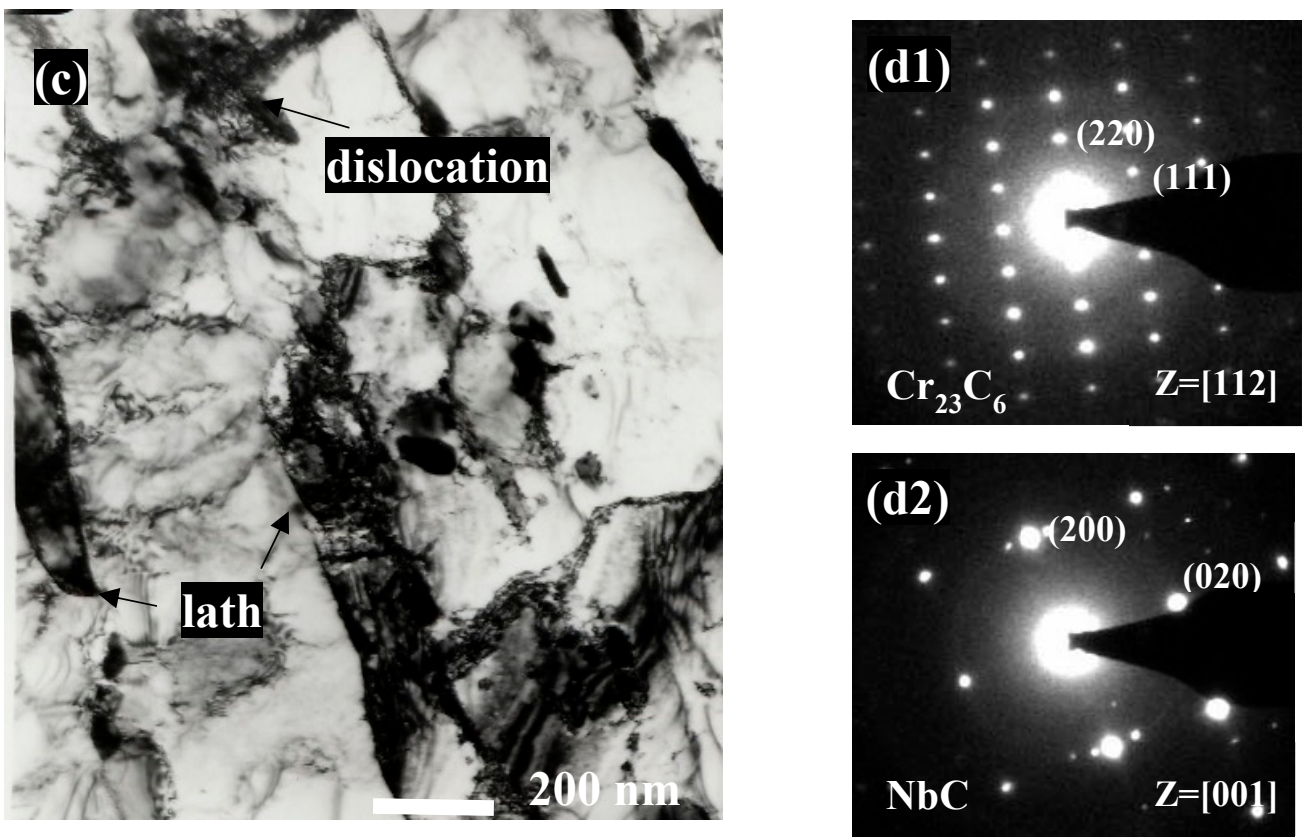

Figure 2. Transmission electron micrographs at each fatigue damage fraction of $600 \mathrm{~s}$ hold time showing dislocation substructures and precipitates; (a) as-tempered, (b) $0.2 N_{f},(\mathbf{c}) 1 N_{f}$, (d1) selective area diffraction (SAD patterns of $\mathrm{Cr}_{23} \mathrm{C}_{6}$ and (d2) SAD patterns of $\mathrm{NbC}$.

The precipitates slightly increased after fatigue failure of $600 \mathrm{~s}$ hold time as shown in Figure 3. The total increase in the size of the precipitates was less than $10 \%$. The agglomeration and coarsening at the grain boundaries and lath interfaces were dominant during the creep-fatigue damage. The $\mathrm{M}_{23} \mathrm{C}_{6}$ carbides were present as $(\mathrm{Cr}, \mathrm{Fe}, \mathrm{Mo})_{23} \mathrm{C}_{6}$ and $\left(\mathrm{Nb}_{X} \mathrm{~V}_{1-\mathrm{X}} \mathrm{CN} ; \mathrm{MX}\right)$ types, where $x$ varies from one to zero. Laves $\mathrm{Fe}_{2}(\mathrm{Mo}, \mathrm{W})$ phases were reported to nucleate on martensite lath boundaries during long term aging, fatigue, and creep deformation, with a high growth rate, which has a significant effect on the decrease of creep strength $[23,24]$. However, no Laves phase was found in the $9 \mathrm{Cr}$ steels during creep-fatigue at $550{ }^{\circ} \mathrm{C}$. The selected area diffraction patterns indicated $\mathrm{Cr}_{23} \mathrm{C}_{6}$ carbide and $\mathrm{NbC}$ carbide. The number of precipitates was measured by image software for the 10 micrographs.
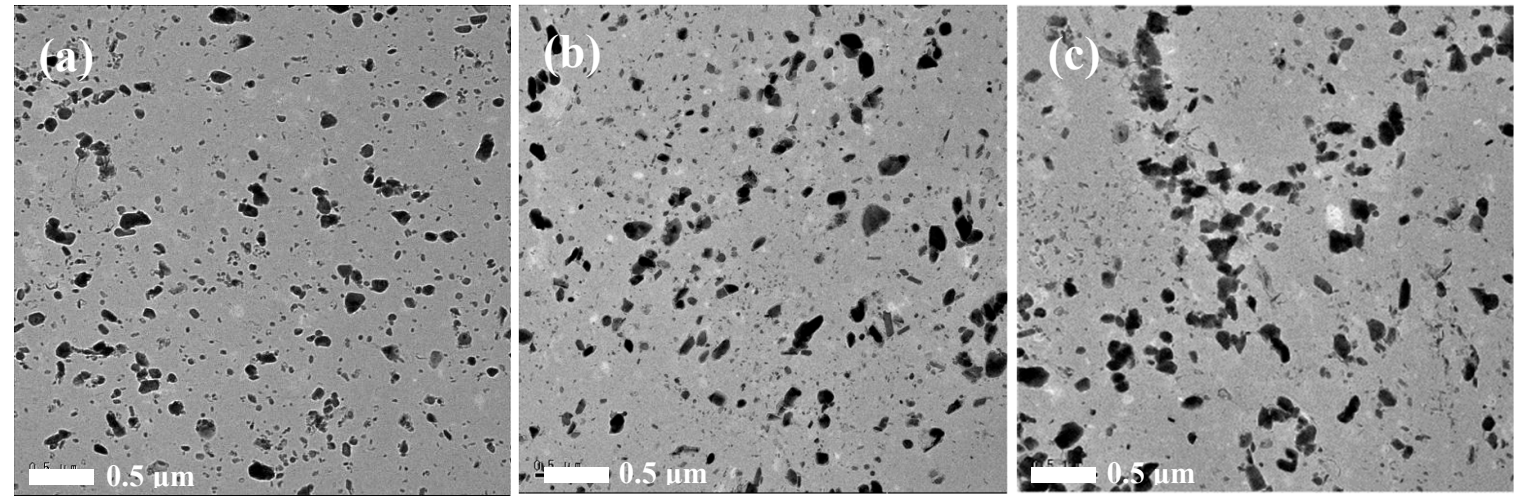

Figure 3. Transmission electron microscopy (TEM) micrographs showing the variation in precipitates morphology of $600 \mathrm{~s}$ hold time; (a) $0.1 N_{f}$, (b) $0.2 N_{f}$, and (c) $1 N_{f}$.

The study of particle effects on the magnetic properties of steels is complicated by the inhomogeneous distribution of some precipitates, which preferentially nucleate on grain boundaries, and also due to the ferromagnetic nature of $\mathrm{Fe}_{3} \mathrm{C}$ and some other carbides below their Curie temperatures. Figure 4 shows the relation between dynamic coercivity and the number of precipitates of each sample. 
The nonlinear curve fits with the allometric model. The dynamic coercivity is closely related to the number of $\mathrm{Cr}_{23} \mathrm{C}_{6}$ precipitates $\left(N^{0.8}\right)$ having a correlation coefficient of 0.85 . In this study, the primary precipitates are the $\mathrm{M}_{23} \mathrm{C}_{6}$ and $(\mathrm{Nb}, \mathrm{V}) \mathrm{C}$ carbides in the ferritic $9 \mathrm{Cr}$ steel, which are analyzed by the SEM and TEM. Even though the $(\mathrm{Nb}, \mathrm{V}) \mathrm{C}$ carbide does not noticeably change due to being very stable at high temperature, the $\mathrm{M}_{23} \mathrm{C}_{6}$ carbide is slightly changed during the creep-fatigue test. Therefore, this $\mathrm{M}_{23} \mathrm{C}_{6}$ carbide possibly acts as an obstacle to the Bloch wall pinning site.

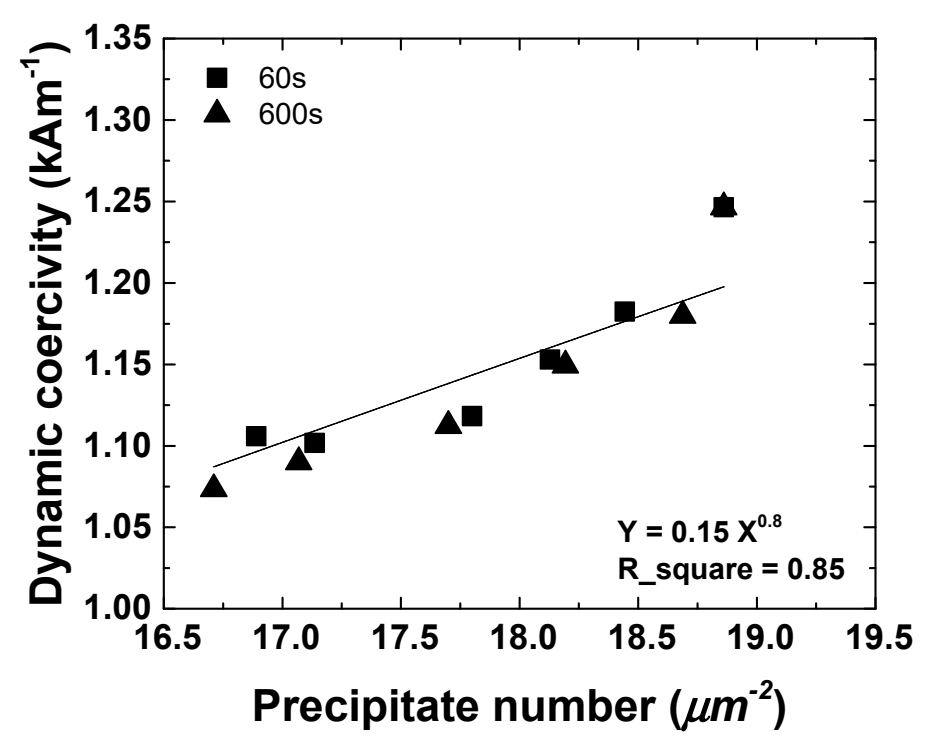

Figure 4. The interrelationship between dynamic coercivity and precipitate number which is fitted to a nonlinear curve by the allometric model $\left(y=a x^{b}\right)$.

Wörner et al. calculated the area variation of the boundaries due to the pinning effect of the inclusion. They proposed an analytical expression for the interaction potential between 180 Bloch walls and nonmagnetic obstacles such as precipitates and pores. The energy per area of the wall boundary is associated with each pinning center. The coercive field is as the following equation [15].

$$
H \mathrm{c}=\mathrm{K}\left(\frac{\pi \sigma_{0} R}{2 \mu_{0} M_{s}}\right) N^{2 / 3}
$$

where $K=1.09, \sigma_{0}$ is energy surface density, $R$ is the radius of the nonmagnetic particle, $\mu_{0}$ is the permeability of free space, $M_{\mathrm{s}}$ is the magnetization of the saturated state, and $N$ is the particle concentration of pinning center.

In this study, the $\mathrm{Cr}_{23} \mathrm{C}_{6}$ and $\mathrm{MX}$ precipitates are nonmagnetic particles and can be considered as pinning obstacles to the 180 Bloch wall movement in $9 \mathrm{Cr}$ ferritic steel. The MX type precipitates are very stable at this test temperature due to their high-temperature stability. Therefore, there are no changes in size and volume fraction during creep-fatigue, although $\mathrm{Cr}_{23} \mathrm{C}_{6}$ precipitates change their shape and coarsened during creep-fatigue. The number of precipitates reduced with the fatigue cycles as already shown in TEM micrographs. The relationship between dynamic coercivity and precipitate concentration can be obtained as shown in Figure 4. In this study, the dynamic coercivity depends on the $\mathrm{Cr}_{23} \mathrm{C}_{6}$ precipitate concentration with $N^{0.8}$ more than $N^{2 / 3}$. This discrepancy may be caused by several microstructural characteristics of materials but, in this study, there are difficulties in measuring the nano-size precipitates with an image analyzer. Therefore, it is not considered the dependence of nano-size precipitates and less than several tens of nanometer particles on the dynamic coercivity.

In addition, plastic deformation evolves lattice defects in materials such as vacancy and dislocation. It creates a significant increase in dislocation density and dislocation tangles are believed to be the pinning sites of domain wall movement [8,9]. This dislocation may exert a force on the domain wall 
and play the role of obstacles to the 180 Bloch wall movement. Figure 5 shows the relation between dynamic coercivity and dislocation density at each sample. The nonlinear curve is fitting with the allometric model. The dynamic coercivity is nonlinearly related to dislocation density $\left(\rho^{0.4}\right)$ having a high correlation coefficient of 0.93 . Takahashi et al. suggested that the magnetization proceeds by the domain wall motion, then the coercivity force can be calculated as follows [25].

$$
H c=\frac{1}{\left(2 M_{S} F \cos \varphi\right)}\left(\frac{\partial E_{\omega}}{\partial x}\right)
$$

where $F$ is the total area of the domain wall in the unit volume, $\varphi$ is the angle between the normal of Bloch wall and $H$, and $E_{\omega}$ is the domain wall energy.

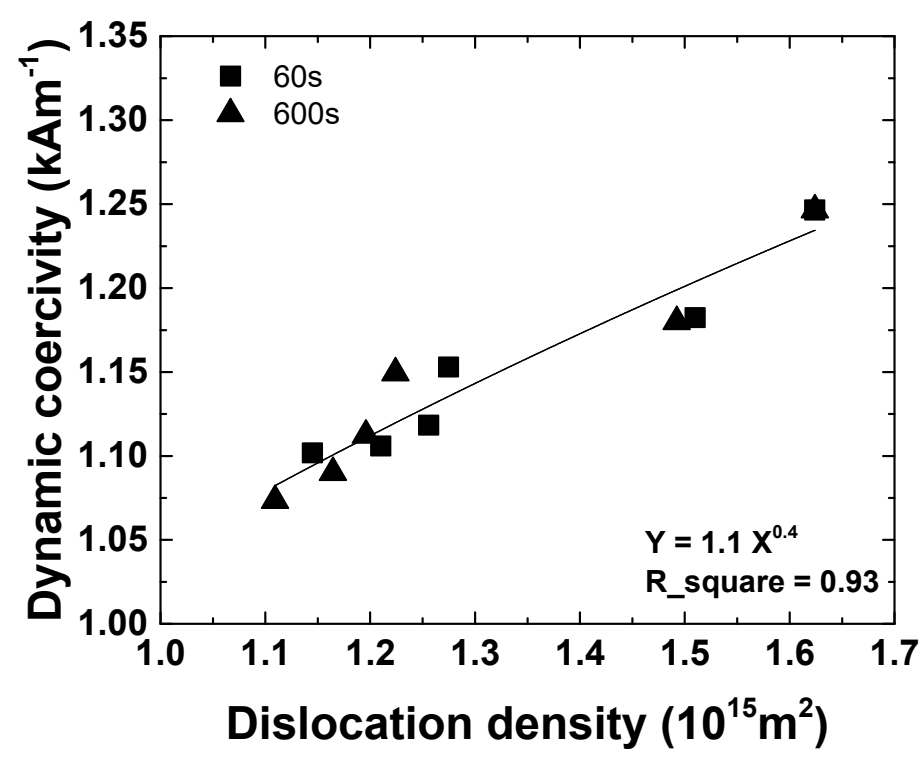

Figure 5. The interrelationship between dynamic coercivity and dislocation density is fitted to a nonlinear curve by the allometric model $\left(y=a x^{b}\right)$.

The domain wall energy strictly depends on the strain field of lattice defects so that it may be calculated and proportional to dislocation density $(\sqrt{ } \rho)$ [25]. With increased internal stress, the critical field required to move a domain wall across a pinning site, and implicitly the wall energy gradient, increases. Dislocation tangles are energetically significant enough to produce effective pinning sites for domain walls $[8,9]$. Dislocation density increases during plastic deformation lead to changes in the domain wall energy gradient at pinning sites. In this study, the dynamic coercivity depends on the dislocation density with $\rho^{0.4}$ more than $\sqrt{ } \rho$. This discrepancy may be caused by the complexity of material microstructures such as precipitates, grain boundaries, lath boundaries, etc. Results concluded that as a result of magnetic measurement the dynamic coercivity of tempered ferritic $9 \mathrm{Cr}$ steel subjected to creep-fatigue at $550{ }^{\circ} \mathrm{C}$ decreased with creep-fatigue cycles. In addition, the dynamic coercivity had a good nonlinear relation with dislocation density and precipitate number.

\section{Conclusions}

In the present study, the dynamic coercivity of ferritic $9 \mathrm{Cr}$ steel was evaluated nondestructively. The microstructural evolution was characterized and interpreted concerning the dynamic coercivity. The dynamic coercivity was obtained from the reversible permeability profiles by the yoke type probe. Creep-fatigue caused coarsening of the $\mathrm{M}_{23} \mathrm{C}_{6}$ carbides and also recovered dislocation resulting in mechanical softening. The decrease in dynamic coercivity with creep-fatigue cycles and test duration was related to the decrease in the number of pinning sites, dislocation density, and precipitate concentration. Vickers's hardness shows a well linear relationship with dynamic coercivity. Further, the 
dynamic coercivity is closely related to the number of $\mathrm{Cr}_{23} \mathrm{C}_{6}$ precipitates with $N^{0.8}$ and the dislocation density with $\rho^{0.4}$. In conclusion, it can nondestructively evaluate the effects of the precipitate and dislocation density on the dynamic coercivity of ferritic steel during creep-fatigue.

Funding: This research received no external funding.

Acknowledgments: This study was supported by a research fund from Chosun University, 2018

Conflicts of Interest: The author declares no conflicts of interest.

\section{References}

1. Abe, F. Research and Development of Heat-Resistant Materials for Advanced USC Power Plants with Steam Temperatures of $700{ }^{\circ} \mathrm{C}$ and Above. Engineering 2015, 1, 211-224. [CrossRef]

2. Kim, C.S. Mechanical softening of tempered martensitic steel depending on long-term aging and creep. Mater. Res. Innov. 2015, 19, 1016-1019. [CrossRef]

3. Abe, F.; Horiuchi, T.; Taneike, M.; Sawada, K. Stabilization of martensitic microstructure in advanced $9 \mathrm{Cr}$ steel during creep at high temperature. Mater. Sci. Eng. A 2004, 378, 299-303. [CrossRef]

4. Gao, Q.; Zhang, Y.; Zhang, H.; Li, H.; Qu, F.; Han, J.; Lu, C.; Wu, B.; Lu, Y.; Ma, Y. Precipitates and Particles Coarsening of 9Cr-1.7W-0.4Mo-Co Ferritic Heat-Resistant Steel after Isothermal Aging. Sci. Rep. 2017, 7, 1-11. [CrossRef] [PubMed]

5. Liu, Z.; Liu, Z.H.; Chen, Z.; Wang, X.; Bao, H.; Dong, C. Microstructure and creep strength evolution in G115 steel during creep at $650^{\circ} \mathrm{C}$. Mater. Res. Express 2020, 7, 016528. [CrossRef]

6. Blaow, M.M.; Sha, B.A. Evaluation of annealing stages in steel using magnetic Barkhausen noise. IJEAT 2014, 1, 1-7.

7. Reddy, K.A. Non-destructive Testing, Evaluation of Stainless Steel Materials. Mater. Today Proc. 2017, 4, 7302-7312. [CrossRef]

8. Kim, C.S. Nondestructive evaluation of strain-induced phase transformation and damage accumulation in austenitic stainless steel subjected to cyclic loading. Metals 2018, 8, 14. [CrossRef]

9. Bong, C.J.; Ryu, K.S.; Nahm, S.H.; Kim, E.K. Degradation Evaluation of Mechanical Property for Modified 9Cr-1Mo Steel by Reversible permeability. J. Magn. 2011, 16, 42-45. [CrossRef]

10. Feu, F.; Trueba, A. Nonlinear reversible processes in YIG: An explanation for the Rayleigh loop anomalies. J. Appl. Phys. 1974, 45, 5033-5036. [CrossRef]

11. Sgobba, S. Physics and measurements of magnetic materials; CERN-2010-004. arXiv 2011, arXiv:1103.1069.

12. Liu, J.; Wilson, J.; Davis, C.L.; Peyton, A. Magnetic characterization of grain size and precipitate distribution by major and minor BH loop measurement. J. Magn. Magn. Mater. 2019, 481, 55-67. [CrossRef]

13. Landgraf, F.J.G.; da Silveira, J.R.F.; Rodrigues, D., Jr. Determining the effect of grain size and maximum induction upon coercive field of electrical steel. J. Magn. Magn. Mater. 2011, 323, 2335-2339. [CrossRef]

14. Adler, E.; Pfeiffer, H. The Influence of Grain Size and Impurities on the Magnetic Properties of the Soft Magnetic Alloy 47.5\% NiFe. IEEE Trans. Magn. Mag. 1974, 10, 172-174. [CrossRef]

15. Wörner, C.H.; Valdés, J.E. On the pinning of domain walls in low magnetization materials. J. Appl. Phys. 1988, 63, 4324-4326. [CrossRef]

16. Fidler, J.; Kirchmayer, H.; Skalicky, P. Pinning of magnetic domain walls at dislocations and precipitates in $\mathrm{Co}_{5}$ Sm crystal. Philos. Mag. B 1981, 43, 765-780. [CrossRef]

17. Bradley, D.E. Replica techniques in applied electron microscopy. J. R. Microsc. Soc. 1960, 79, 101-118. [CrossRef]

18. Metzger, T.; Höpler, R.; Born, E.; Ambacher, O.; Stutzann, M.; Stömmer, R.; Schuster, M.; Göbel, H.; Christiansen, S.; Albrecht, M.; et al. Defect structure of epitaxial GaN films determined by transmission electron microscopy and tripleaxis X-ray diffractometry. Philos. Mag. 1998, 77, 1013-1025. [CrossRef]

19. Ryu, K.S.; Nahm, S.H.; Park, J.S.; Yu, K.M.; Kim, Y.B.; Son, D. A new non-destructive method for estimating the remanent life of a turbine rotor steel by reversible magnetic permeability. J. Magn. Magn. Mater. 2002, 251, 196-201. [CrossRef]

20. Byeon, J.W.; Kwun, S.I. Magnetic nondestructive evaluation of thermally degraded 2.25Cr-1Mo steel. Mater. Lett. 2003, 58, 94-98. [CrossRef] 
21. Kim, C.S. Influcence of precipitate and martensite lath on the magnetic properties in creep damaged 11Cr-3.45W steel. Mater. Trans. 2007, 80, 3028-3030. [CrossRef]

22. Abe, F. Coarsening behavior of lath and its effect on creep rates in tempered martensitic $9 \mathrm{Cr}-\mathrm{W}$ steels. Mater. Sci. Eng. A 2004, 378, 565-569. [CrossRef]

23. Abe, F. Effect of fine precipitation and subsequent coarsening of $\mathrm{Fe}_{2} \mathrm{~W}$ laves phase on the creep deformation behavior of tempered martensitic $9 \mathrm{Cr}-\mathrm{W}$ steel. Metall. Mater. Trans. A 2005, 36, 321-332. [CrossRef]

24. Kim, C.S. Nanosized-precipitate behavior of ferritic $11 \mathrm{Cr}$ heat-resistance steel subjected to high temperature creep damage. J. Nanosci. Nanotechnol. 2019, 19, 2421-2425. [CrossRef] [PubMed]

25. Takahashi, S.; Echigoya, J.; Motoki, Z. Magnetization curves of plastically deformed Fe metals and alloys. J. Appl. Phys. 2000, 87, 805-813. [CrossRef]

(C) 2020 by the author. Licensee MDPI, Basel, Switzerland. This article is an open access article distributed under the terms and conditions of the Creative Commons Attribution (CC BY) license (http://creativecommons.org/licenses/by/4.0/). 